\title{
SITE PREFERENCE OF Gd IN SYNTHETIC FLUORAPATITE BY SINGLE-CRYSTAL W-BAND EPR AND X-RAY REFINEMENT OF THE STRUCTURE: A COMPARATIVE STUDY
}

\author{
YUANMING PAN P $^{\S}$ \\ Department of Geological Sciences, University of Saskatchewan, Saskatoon, Saskatchewan S7N 5E2, Canada
}

Michael E. FLEET

Department of Earth Sciences, University of Western Ontario, London, Ontario N6A 5B7, Canada

NING CHEN

Department of Geological Sciences, University of Saskatchewan, Saskatoon, Saskatchewan S7N 5E2, and Canadian Light Source, University of Saskatchewan, Saskatoon, Saskatchewan S7N 5C6, Canada

JOHN A. WEIL

Department of Chemistry, University of Saskatchewan, Saskatoon, Saskatchewan S7N 5C9, Canada

MARK J. NILGES

Illinois EPR Research Center, University of Illinois at Urbana-Champaign, Illinois 61801, U.S.A.

\begin{abstract}
Fluorapatite containing 1.2(2) wt $\% \mathrm{Gd}_{2} \mathrm{O}_{3}$ (sample AP30-1), synthesized from a $\mathrm{CaF}_{2}$-rich melt in a Pt crucible, has been investigated by single-crystal W-band $(\sim 94 \mathrm{GHz})$ electron paramagnetic resonance (EPR) spectroscopy and X-ray structure refinement. The EPR spectrum of AP30-1 measured at $\sim 287 \mathrm{~K}$, with Zeeman field $\mathbf{B} / / \mathbf{z}$ ' and microwave field $\mathbf{B}_{\mu} / / \mathbf{x}^{\prime}$, gave a Gd site-occupancy ratio $\left({ }^{\mathrm{Ca} 2} \mathrm{Gd} /{ }^{\mathrm{Ca} 1} \mathrm{Gd}\right)$ of $1.4(4)$, indicating a weak preference between the two types of $\mathrm{Ca}$ sites. Similarly, X-ray refinement of the structure of AP30-1 suggests that Gd is essentially equally distributed between the two Ca sites: ${ }^{\mathrm{Ca} 2} \mathrm{Gd} /{ }^{\mathrm{Ca} 1} \mathrm{Gd}$ $=0.8(2)$, although the Gd content in this sample is close to the practical limit of detection of this method. This agreement between the W-band EPR and X-ray structural data confirms that EPR is capable of determining the distribution of paramagnetic trace elements between structurally nonequivalent positions in minerals. X-ray refinement of the structure of another sample of fluorapatite [AP40-0, containing 2.9(1) wt $\% \mathrm{Gd}_{2} \mathrm{O}_{3}$ ] synthesized in a sealed Pt capsule, yielded a ${ }^{\mathrm{Ca} 2} \mathrm{Gd} /{ }^{\mathrm{Ca} 1} \mathrm{Gd}$ value of $3.1(6)$, indicating a marked preference for the $\mathrm{Ca} 2$ site, consistent with the site preference of $\mathrm{Gd}$ in hydrothermally grown Gd-rich fluorapatite. The marked preference of $\mathrm{Gd}$ for the $\mathrm{Ca} 1$ site observed in previous EPR studies of flux-grown fluorapatite samples [AP30-0, 0.8(1) ppm Gd and ${ }^{\mathrm{Ca} 2} \mathrm{Gd} /{ }^{\mathrm{Cal}} \mathrm{Gd}=0.13$; AP30-5, 57(4) ppm Gd and ${ }^{\mathrm{Ca} 2} \mathrm{Gd} / \mathrm{Ca}^{\mathrm{Ca}} \mathrm{Gd}=0.20$ ] is now attributed to the presence of $\mathrm{Ca}^{2+}$ vacancies at ppm concentrations in these crystals. These point defects are unlikely to reach appreciable (weight $\%$ ) concentrations in fluorapatite crystals synthesized from $\mathrm{CaF}_{2}$-rich melts, and hence the normal preference of $\mathrm{Gd}$ for the $\mathrm{Ca} 2$ site in AP30-1 and AP40-0.
\end{abstract}

Keywords: gadolinium, fluorapatite, single-crystal W-band EPR, X-ray structure refinement, site preference, substitution mechanisms, point defects.

\section{SOMMAIRE}

Nous avons étudié un monocristal de fluorapatite contenant 1.2(2)\% $\mathrm{Gd}_{2} \mathrm{O}_{3}$ par poids (AP30-1), synthétisé à partir d'un bain fondu de $\mathrm{CaF}_{2}$ dans un récipient en platine, au moyen de la résonance paramagnétique des électrons (RPE) dans la bande $\mathrm{W}$ ( 94 $\mathrm{GHz}$ ) et par affinement de la structure par diffraction X. Le spectre RPE de AP30-1, mesuré à 287 K, avec un champ Zeeman $\mathbf{B} / / \mathbf{z}$ ' et un champ micro-onde $\mathbf{B}_{\mu} / / \mathbf{x}^{\prime}$, indique un rapport de l'occupation des sites Ca par le $\mathrm{Gd}\left({ }^{\mathrm{Ca} 2} \mathrm{Gd} /{ }^{\mathrm{Ca}} \mathrm{Gd}\right) \mathrm{de} 1.4(4)$, et donc

§ E-mail address: yuanming.pan@usask.ca 
une légère différence en préférence entre les deux sortes de sites Ca. De même, l'affinement de la structure de AP30-1 montre que le $\mathrm{Gd}$ serait réparti essentiellement également entre les deux sites: ${ }^{\mathrm{Ca}}{ }^{\mathrm{Gd}} /{ }^{\mathrm{Ca}} \mathrm{Gd}=0.8(2)$, quoique la teneur en $\mathrm{Gd}$ dans cet échantillon se rapproche de la limite de détection de cette méthode. Cette concordance entre la bande W du spectre RPE et les données sur la structure confirme que la spectroscopie RPE constitue un moyen révélateur pour déterminer la distribution des éléments traces paramagnétiques distribués sur des sites non-équivalents des minéraux. L'affinement de la structure d'un autre échantillon de fluorapatite [AP40-0, contenant 2.9(1)\% de $\mathrm{Gd}_{2} \mathrm{O}_{3}$ (poids)], synthétisé dans une capsule de platine, a donné une valeur ${ }^{\mathrm{Ca} 2} \mathrm{Gd} /{ }^{\mathrm{Ca} a} \mathrm{Gd}$ de 3.1(6), indiquant une préférence marquée pour le site Ca2, ce qui concorde avec la préférence du $\mathrm{Gd}$ pour ce site dans la fluorapatite riche en Gd synthétisée en milieu hydrothermal. La préférence marquée du Gd pour le site Ca1, signalée dans des études antérieures de fluorapatite synthétisée dans un flux $\left[\mathrm{AP} 30-0,0.8(1) \mathrm{ppm}\right.$ Gd et ${ }^{\mathrm{Ca} 2} \mathrm{Gd} /{ }^{\mathrm{Ca} 1} \mathrm{Gd}=0.13$; $\mathrm{AP} 30-5,57(4) \mathrm{ppm} \mathrm{Gd}$ et ${ }^{\mathrm{Ca} 2} \mathrm{Gd} /{ }^{\mathrm{Ca} 1} \mathrm{Gd}=0.20$ ], semble maintenant attribuable à la présence de lacunes dans le site Ca en concentrations se rapprochant du ppm dans ces cristaux. Il est peu probable que ces défauts ponctuels dans le réseau atteignent des proportions importantes (de l'ordre du pourcent) dans les cristaux de fluorapatite synthétisés à partir d'un bain fondu riche en $\mathrm{CaF}_{2}$, et donc c'est la préférence normale du Gd pour le site Ca2 qui se manifeste dans les échantillons AP30-1 et AP40-0.

(Traduit par la Rédaction)

Mots-clés: gadolinium, fluorapatite, spectroscopie RPE (bande W, monocristal), affinement de la structure, préférence des sites, mécanismes de substitution, défauts ponctuels.

\section{INTRODUCTION}

Apatite-group minerals, particularly fluorapatite (FAp) and, to a lesser extent, hydroxylapatite (OHAp) and chlorapatite (ClAp), are among the most important hosts of rare-earth elements $(R E E)$ in igneous, metamorphic and sedimentary rocks, as well as in the biomass (e.g., Gromet \& Silver 1983, Pan \& Fleet 1996, Pan \& Stauffer 2000, Dymek \& Owens 2001). Consequently, extensive studies have been made to investigate intrinsic and external controls on the uptake of the REE in apatite-group minerals (e.g., Watson \& Capobianco 1981, Kovalenko et al. 1982, Watson \& Harrison 1984), including our own recent efforts combining hydrothermal experiments and single-crystal X-ray studies of the structure (Fleet \& Pan 1995, 1997a, b, Fleet et al. 2000a, b). Previously, all of our X-ray structure work on synthetic apatite was performed on $R E E$-rich crystals, with $R E E$ contents ranging from $1.6(3) \mathrm{wt} \% \mathrm{La}_{2} \mathrm{O}_{3}$ in $\mathrm{ClAp}$ (Fleet et al. 2000a) to 12.7(5) wt $\% \mathrm{Nd}_{2} \mathrm{O}_{3}$ in FAp (Fleet \& Pan 1995). Similarly, existing structural data about the REE in natural FAp samples were all obtained from $R E E$-rich crystals (e.g., Hughes et al. 1991). A question that arises is whether these data from $R E E$-rich crystals can be extended to natural apatite-group phases that commonly contain only part-per-million (ppm) levels of the REE. In order to answer this question, we turned to single-crystal electron paramagnetic resonance (EPR) spectroscopy for the structural characterization of ppmand sub-ppm-level $\mathrm{Gd}^{3+}$, as a representative of trivalent REE, in flux-grown FAp (Chen et al. 2002a, b, Pan et al. 2002).

One notable finding of the single-crystal EPR studies at W-band frequency $(\sim 94 \mathrm{GHz})$ is that $\mathrm{Gd}$ at ppmand sub-ppm-level concentrations in FAp has a marked preference for the Ca1 site (Chen et al. 2002b, Pan et al. 2002 ), opposite to that in $R E E$-rich FAp as inferred from X-ray structure studies (e.g., Hughes et al. 1991, Fleet $\&$ Pan 1995). EPR has long been applied to the deter- mination of the distribution of paramagnetic trace elements over structurally nonequivalent positions in minerals and their synthetic analogues (e.g., Schindler \& Ghose 1970, Warren 1970, Calas 1988, references therein). However, the site occupancies determined in previous EPR studies usually were not verified because of the lack of independent techniques for structural characterization of trace elements in solids. Accordingly, a comparative study using both single-crystal W-band EPR and X-ray structure techniques was initiated on a flux-grown FAp, and the resulting data are reported herein. Specifically, sample AP30-1 selected for the present study was used previously for the characterization of a Gd ${ }^{3+}$ center by X-band $(\sim 9.4 \mathrm{GHz})$ EPR and was shown by electron-microprobe analysis to contain 1.2(2) $\mathrm{wt} \% \mathrm{Gd}_{2} \mathrm{O}_{3}$ (Chen et al. 2002a), which is amenable to EPR but is close to the capability limit of X-ray structure refinement (see below). Therefore, another FAp sample (AP40-0 containing a higher Gd content in the starting material) was synthesized for X-ray structure refinement to test the results obtained with AP301. The data reported herein confirm that EPR is capable of providing reasonable estimates of site occupancies of paramagnetic trace elements in minerals and their synthetic analogues. Moreover, the results of this study, in conjunction with data from our previous singlecrystal W-band EPR studies (Chen et al. 2002b, Pan et al. 2002), provide new insight into the control of mechanisms of substitution (Mackie \& Young 1973, Pan \& Fleet 2002), particularly the role of vacancies at the $\mathrm{Ca}^{2+}$ sites, on the site preference of trivalent REE in fluorapatite.

\section{BACKGROUND INFORMATION}

Electron paramagnetic resonance (EPR) spectroscopy is based on the quantitative measurement of the net resonant absorption and emission of microwave electromagnetic radiations by molecules, free radicals 
and defect centers with unpaired electron(s) (i.e., paramagnetic species). EPR is a powerful structural probe of dilute paramagnetic centers in various materials (including minerals and fluids), but has not yet been extensively applied in the Earth sciences (Calas 1988, Weil et al. 1994). The EPR transition energies of paramagnetic trace ions in minerals are sensitive to the surrounding crystal field. Therefore, quantitative analysis of EPR spectra can provide detailed information about the state and local structural environments of the paramagnetic ions, e.g., oxidation state, coordination number, and polyhedron symmetry, and local distortion. In some favorable cases, occupancies among different crystallographic sites can be obtained (Calas 1988, Chen et al. 2002a, b).

Field-swept (fixed-frequency) EPR spectra are commonly presented as the first derivative $(\mathrm{dF} / \mathrm{dB})$ of the absorption versus the magnetic field $\mathrm{B}$, rather than the absorption line F(B) itself. The concentration (commonly expressed as the number of spins) of paramagnetic centers then is proportional to $\int \mathrm{FdB}$, i.e., the doubly integrated first-derivative signal (Calas 1988). Thus the relative concentrations of paramagnetic trace ions over crystallographically nonequivalent sites (i.e., site-occupancy ratios) in minerals can be estimated by comparing such doubly integrated values, i.e., areas I beneath the $\mathrm{F}(\mathrm{B})$ curves (e.g., Schindler \& Ghose 1970). Note that EPR also distinguishes paramagnetic centers among magnetically nonequivalent but chemically identical positions, which in favorable cases may be directly assignable to crystallographic sites in minerals.

\section{EXPERIMENTAL Procedures}

Experimental details for the synthesis of sample AP30-1 (crystals up to $1 \mathrm{~cm}$ in length and $\geq 1 \mathrm{~mm}$ in diameter) in a tightly covered platinum crucible (in air), using the flux method of Prener (1967), were given in Chen et al. (2002a). Sample AP40-0 was synthesized by use of similar experimental procedures and starting materials, except that a mixture of $\sim 100 \mathrm{mg}$ starting materials containing $\sim 15 \mathrm{wt} \% \mathrm{Gd}_{2} \mathrm{O}_{3}$ was sealed in a platinum capsule by welding. Crystals of AP30-1 and AP40-0 were analyzed on a JEOL JXA-8600 electron microprobe at the University of Saskatchewan, operated at an accelerating voltage of $10 \mathrm{kV}$, beam current of 10 $\mathrm{nA}$, beam diameter of $5 \mu \mathrm{m}$, and counting times of $30 \mathrm{~s}$ for $\mathrm{Ca}, \mathrm{P}$ and $\mathrm{F}$. The same spots of the FAp crystals were re-analyzed at an accelerating voltage of $15 \mathrm{kV}$, but at the same beam current and diameter, to include Gd (counting time of $90 \mathrm{~s}$ ), in addition to $\mathrm{Ca}, \mathrm{P}$ and $\mathrm{F}$ (30 s). Following Stormer et al. (1993), all microprobe analyses of FAp crystals were made on sections approximately parallel to the $c$ axis in order to minimize the possible diffusion of $\mathrm{F}$ anions under the influence of the electron beams. Standards included a natural FAp for $\mathrm{Ca}$ and $\mathrm{P}$, synthetic phlogopite for $\mathrm{F}$, and synthetic $\mathrm{GdPO}_{4}$ for Gd. Also, a well-characterized sample of
Durango fluorapatite (Young et al. 1969) was used as a secondary standard to monitor the F results (Table 1).

\section{Single-crystal W-band EPR measurements}

Single-crystal W-band EPR spectra of AP30-1 were measured at $\sim 287 \mathrm{~K}$ on a Mark-II spectrometer at the Illinois EPR Research Center, University of Illinois at Urbana-Champaign. Unlike those spectra obtained in the previous experiments (Chen et al. 2002a, b), which were measured with applied Zeeman magnetic field $\mathbf{B}$ in three orthogonal rotation planes designed for the optimization of the spin-hamiltonian parameters of unknown paramagnetic centers, the EPR spectra used in this study were collected for $\mathbf{B}$ in one plane (i.e., x'z') only. Following Chen et al. (2002a, b), we denote the actual experimental coordinate system by $\mathbf{x}^{\prime} \mathbf{y}^{\prime} \mathbf{z}$ ' to distinguish it from the ideal coordinate system $\mathbf{x y z}$ to deal with the (unavoidable) errors in crystal alignment in $\mathrm{W}$ band experiments, where axes $\mathbf{y}$ and $\mathbf{z}$ are chosen along the crystallographic axes a and $\mathbf{c}$, respectively, and axis $\mathbf{x}$ is defined as perpendicular to both $\mathbf{y}$ and $\mathbf{z}$. For measurements in plane $x^{\prime} z$ ', a prismatic crystal of FAp was first mounted on a quartz rod by attaching a well-developed crystal face to the flat end of the quartz rod (i.e., the crystal face perpendicular to the rod axis), and was then inserted into the resonant cavity of the W-band spectrometer. Alignment was made by trial runs on the basis that the two well-characterized $\mathrm{Gd}^{3+}$ centers (' $\mathrm{a}$ ' and ' $b$ ') do not exhibit any magnetic-site splitting at $\mathbf{B} / / \mathbf{z}$ and microwave excitation in a magnetic field $\mathbf{B}_{\mu} / / \mathbf{x}$ (Chen et al. 2002a, b). Field-swept EPR experiments were made at $5 \%$ and $10 \%$ intervals, with a spectral resolution of $4.9 \mathrm{G}$ (i.e., 4,096 field data-points over 20,000 G).

TABLE 1. COMPOSITION OF FLUORAPATITE CRYSTALS

\begin{tabular}{|c|c|c|c|c|}
\hline \multirow[t]{2}{*}{ Samples } & \multirow{2}{*}{$\begin{array}{l}\text { AP30-1 } \\
\mathrm{n}=12(\sigma)\end{array}$} & \multirow{2}{*}{$\begin{array}{l}\text { AP40-0 } \\
n=11(\sigma)\end{array}$} & \multicolumn{2}{|c|}{ Durango FAp } \\
\hline & & & $\mathrm{n}=12(\sigma)$ & Ref \\
\hline $\mathrm{P}_{2} \mathrm{O}_{5}(w t \%)$ & $42.31(48)$ & $41.30(47)$ & $40.68(39)$ & 40.78 \\
\hline $\mathrm{CaO}$ & $55,12(32)$ & $53.21(51)$ & $54.24(33)$ & 54.02 \\
\hline $\mathrm{Gd}_{2} \mathrm{O}_{3}$ & $1.15(21)$ & $2.94(12)$ & $0.00(2)$ & 0.01 \\
\hline F & $3.65(12)$ & $3.53(9)$ & $3.51(14)$ & 3.53 \\
\hline$-\mathrm{O} \equiv \mathrm{F}$ & 1.54 & $1.49^{\circ}$ & 1.44 & 1.45 \\
\hline Total & $100.69(41)$ & $99.49(45)$ & $96.99(37)$ & $99.94^{*}$ \\
\hline Р apfu & 6.00 & 6.00 & & \\
\hline $\mathrm{Ca}$ & 9.91 & 9.80 & & \\
\hline Gd & 0.06 & 0.17 & & \\
\hline$F$ & 1.94 & 1.92 & & \\
\hline
\end{tabular}

All oxide contents were obtained from EMPA at $15 \mathrm{kV}$, whereas the $\mathrm{F}$ values were obtained at $10 \mathrm{kV}$ (see text for discussion); $w t \%$ is weight percent; $n$, number of analyses; $\sigma$, one standard deviation; $a p f u$, atoms per formula unit. Ref. denotes reference data for the Durango fluorapatite (FAp), from Young et al. (1969). * Total includes other oxides 
Single-crystal W-band EPR spectra were also measured on an elongate crystal of sample AP40-0 at room temperature. Unfortunately, these EPR spectra exhibit only very broad lines, making it impossible to distinguish the different paramagnetic centers (e.g., Chen $e t$ al. 2002a, b) in this sample. This pronounced line-broadening effect presumably is related to the high Gd content in this sample (see below).

\section{Single-crystal $X$-ray refinement of the structure}

Single-crystal X-ray-diffraction measurements were made at room temperature and atmospheric pressure with a Nonius Kappa CCD diffractometer and graphite-

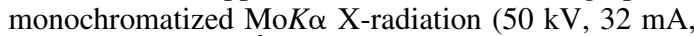
and $\lambda=0.70926 \AA$ ), at the University of Western Ontario. The reflection data were processed with the software packages DENZO and SCALEPACK (University of Texas Southwestern Medical Center at Dallas) and XDISPLAYF (University of Virginia Patent Foundation). SCALEPACK includes an empirical absorption-correction based on intensities of equivalent reflections. Structure refinements were made with LINEX77 (State University of New York at Buffalo). Scattering factors for neutral atomic species and values of $f^{\prime}$ and $f^{\prime \prime}$ ' were taken, respectively, from Tables 2.2A and 2.3.1 of the International Tables for X-ray Crystallography (Ibers \& Hamilton 1974). Experimental details for the two crystals investigated, including the assumed formulae, are given in Table 2, and selected bond-distances and angles are given in Table 3. Tables of observed and calculated structure-factors are available from the Depository of Unpublished Data, CISTI, National Research Council of Canada, Ottawa, Ontario K1A 0S2, Canada.

\section{RESULTS}

\section{Characterization of AP30-1 and AP40-O}

The experimental products and characterization of sample AP30-1 have been described in Chen et al. (2002a). The synthesis of AP40-0 was undertaken in a sealed platinum capsule for the following three reasons: 1) to prevent $\mathrm{F}$ (and $\mathrm{Ca}$ ) loss during the experiment, 2) to test the maximum uptake of $\mathrm{Gd}$ in $\mathrm{FAp}$ from $\mathrm{CaF}_{2}$-rich melts in the absence of extraneous charge-compensating ions (e.g., $\mathrm{Na}^{+}$and $\mathrm{Si}^{4+}$; Fleet \& Pan 1995), and 3) to produce FAp crystals with a higher Gd content than that of AP30-1, for X-ray structure study (see below). The experimental products of AP40-0 included subhedral FAp crystals (up to $\sim 300 \mu \mathrm{m}$ in maximum dimension), quenched $\mathrm{CaF}_{2}$ melt, and unreacted $\mathrm{Gd}_{2} \mathrm{O}_{3}$.

Separate analyses of FAp crystals, including the Durango FAp, at 10 and $15 \mathrm{kV}$ did not reveal any systematic differences in the measured $\mathrm{F}$ contents either in individual grains or between grains. Table 1 shows that the FAp crystals of AP30-1 are close to being stoichio- metric with respect to $\mathrm{F}$ (considering that a minor amount of $\mathrm{F}$ is replaced by $\mathrm{O}$ in the incorporation of $\mathrm{Gd}$ into the $\mathrm{Ca} 2$ site; Chen et al. 2002a) and contain 1.2(2) wt $\% \mathrm{Gd}_{2} \mathrm{O}_{3}$. Similarly, the FAp crystals of AP40-0 are approximately stoichiometric with respect to $\mathrm{F}$, but contain a higher $\mathrm{Gd}$ content [2.9(1) wt $\% \mathrm{Gd}_{2} \mathrm{O}_{3}$; Table 1].

\section{Single-crystal W-band EPR spectra}

The single-crystal W-band EPR spectra of AP30-1 measured with $\mathbf{B}$ in the plane $\mathrm{x}^{\prime} \mathrm{z}$ ' are similar to their respective counterparts of AP30-0 (Pan et al. 2002) and

TABLE 2. DETAILS OF X-RAY STRUCTURE REFINEMENTS OF Gd-DOPED FLUORAPATITE

\begin{tabular}{|c|c|c|c|c|c|c|}
\hline \multicolumn{2}{|l|}{ Sample } & \multicolumn{2}{|c|}{ AP30-1 AP40-0 } & \multicolumn{2}{|r|}{ AP30-1 } & AP40 0 \\
\hline \multirow[t]{5}{*}{ Formula: } & $\mathrm{Ca}$ & 9.91 & 9.80 & Crystal volume & 1.43 & 0.56 \\
\hline & $\mathrm{Gd}$ & 0.06 & 0.17 & $\mathrm{~mm}^{3} \times 10^{3}$ & & \\
\hline & $\mathbf{P}$ & 6.00 & 6.00 & Crystal shape & tablet & prism \\
\hline & 0 & 24.07 & 24.08 & $a(\AA)\left(P G_{3} / m\right)$ & $9.3690(3)$ & $9.3744(2)$ \\
\hline & $\mathbf{F}$ & 1.94 & 1.92 & $c(\AA)$ & $6.8843(2)$ & $6.8848(2)$ \\
\hline \multicolumn{2}{|c|}{ Reflections (unique) } & 408 & 384 & Reflections & 148 & 176 \\
\hline \multicolumn{2}{|c|}{ Refined parameters } & 41 & 41 & I $>3 \sigma(I)$ & & \\
\hline \multicolumn{2}{|l|}{$\mu\left(\mathrm{cm}^{-1}\right)$} & 31.57 & 34.58 & Extinction $\left(\times 10^{4}\right)$ & $1.19(6)$ & $5.0(2)$ \\
\hline \multicolumn{2}{|l|}{$R$} & 0.020 & 0.023 & $\Delta \rho\left(\mathrm{e}^{-3}\right)(+)$ & 0.40 & 0.69 \\
\hline \multicolumn{2}{|l|}{$R_{\mathrm{w}}$} & 0.027 & 0.030 & $\Delta \rho\left(\mathrm{e}^{-3}\right)(-)$ & 0.40 & 0.43 \\
\hline \multicolumn{2}{|l|}{$\mathbf{s}$} & 1.016 & 1.002 & & & \\
\hline
\end{tabular}

TABLE 3. SELECTED BOND DISTANCES ( $\AA$ ) AND ANGLES $\left({ }^{\circ}\right)$ IN SYNTHETIC FLUORAPATITE

\begin{tabular}{|c|c|c|c|c|c|}
\hline \multirow[b]{2}{*}{ Gd (apfu) } & & \multirow{2}{*}{$\begin{array}{l}\text { SMY1 } \\
\ldots .0\end{array}$} & \multirow{2}{*}{$\frac{\mathrm{AP} 30-1}{0.06}$} & \multirow{2}{*}{$\frac{\mathrm{AP}^{40-0}}{-17}$} & \multirow{2}{*}{$\begin{array}{l}\text { FP95 }{ }^{2} \\
-\cdots \\
0.612\end{array}$} \\
\hline & & & & & \\
\hline Cal-Ol & $\times 3$ & 2.397 & $2.398(1)$ & $2.398(1)$ & $2.405(1)$ \\
\hline $\mathrm{Ca} 1-\mathrm{O}^{\mathrm{x}}$ & $\times 3$ & 2.453 & $2.454(1)$ & $2.455(1)$ & $2.457(1)$ \\
\hline $\mathrm{Ca} 1-\mathrm{O}^{\mathrm{a}}$ & $\times 3$ & 2.801 & $2.802(1)$ & $2.803(2)$ & $2.813(1)$ \\
\hline Mean & & 2.550 & 2.552 & 2.552 & 2.558 \\
\hline $\mathrm{Ca} 2-\mathrm{O}^{\mathrm{b}}$ & & 2.814 & $2.688(2)$ & $2.691(2)$ & $2.669(1)$ \\
\hline $\mathrm{Ca} 2-\mathrm{O}^{\mathrm{c}}$ & & 2.384 & $2.374(2)$ & $2.384(2)$ & $2.368(0)$ \\
\hline $\mathrm{Ca} 2-\mathrm{O} 3$ & $\times 2$ & 2.384 & $2.489(1)$ & $2.489(1)$ & $2.498(1)$ \\
\hline $\mathrm{Ca}_{2}-\mathrm{O}^{\mathrm{d}}$ & $\times \overline{2}$ & 2.398 & $2.354(1)$ & $2.358(2)$ & $2.345(1)$ \\
\hline Mean & & 2.460 & 2.458 & 2.462 & 2.454 \\
\hline $\mathrm{Ca} 2-\mathrm{F}$ & & 2.231 & $2.294(0)$ & $2.283(1)$ & $2.313(0)$ \\
\hline $\mathrm{P}-\mathrm{O} 1$ & & 1.534 & $1.531(2)$ & $1.533(2)$ & $1.536(1)$ \\
\hline $\mathrm{P}-\mathrm{O} 2$ & & 1.541 & $1.540(2)$ & $1.541(2)$ & $1.545(1)$ \\
\hline $\mathrm{P}-\mathrm{O} 3$ & $\times 2$ & 1.534 & $1.531(1)$ & $1.532(2)$ & $1.537(1)$ \\
\hline Mean & & 1.536 & 1.533 & 1.535 & 1.539 \\
\hline $\mathrm{O} 1-\mathrm{P}-\mathrm{O} 2$ & & 111.29 & $111.20(9)$ & $111.37(11)$ & $111.20(7)$ \\
\hline $\mathrm{O} 1-\mathrm{P}-\mathrm{O}^{\mathrm{e}}$ & $\times 2$ & 111.06 & $111.14(6)$ & $111.13(7)$ & $111.11(4)$ \\
\hline $\mathrm{O} 2-\mathrm{P}-\mathrm{O} 3$ & $\times 2$ & 107.95 & $107.99(6)$ & $108.06(8)$ & $108.13(4)$ \\
\hline $\mathrm{O} 3-\mathrm{P}-\mathrm{O}^{\mathrm{e}}$ & & 107.38 & $107.22(9)$ & $106.90(11)$ & $107.00(7)$ \\
\hline
\end{tabular}

SMY is the end-member fluorapatite of Sudarsanan et al. (1972); FP95 is the Gd-rich fluorapatite of Fleet \& Pan (1995). a $=-x,-y,-z . \mathrm{b}=-y, x-y, z . \mathrm{c}=y-x,-x, z . \mathrm{d}=$ $\boldsymbol{x}-y, x,-z \cdot \mathbf{e}=x, y, 1 / 2-z$. 
AP30-5 (Chen et al. 2002b). These spectra (e.g., Fig. 1a) are characterized by the presence of two distinct $\mathrm{Gd}^{3+}$ centers (i.e., the recently established centers ' $a$ ' and ' $b$ ' containing $\mathrm{Gd}^{3+}$ ions at the sites $\mathrm{Ca} 2$ and Ca1, respectively; Chen et al. 2002a, b). The individual spectral lines of the $\mathrm{Gd}^{3+}$ centers in AP30-1, however, are noticeably broader than their counterparts in AP300 and AP30-5 (Fig. 1), largely because of the appreciably higher Gd content and resulting stronger dipolar interactions between the $\mathrm{Gd}^{3+}$ ions in the former (Chen et al. 2002a). Other spectral lines related to unknown paramagnetic center(s) are also present in the spectra of AP30-1 (Fig. 1a). However, the $\mathrm{Mn}_{\mathrm{I}}$ center and a defect center possibly involving two ${ }^{19} \mathrm{~F}$ or ${ }^{31} \mathrm{P}$ nuclei (Pan et al. 2002), which are clearly resolved in the singlecrystal W-band spectra of AP30-0 and AP30-5 (Fig. $1 \mathrm{~b}, \mathrm{c})$, are not detectable in AP30-1.

The relative abundance of centers ' $a$ ' and ' $b$ ' in AP30-1 has been estimated by comparison between observed and simulated single-crystal W-band EPR spectra, because a direct double integration of the first derivative of the absorption lines (e.g., Schindler \& Ghose 1970) is not possible here owing to significant line-broadening and consequent peak-overlap (at the central electronic transitions) related to the high $\mathrm{Gd}$ content in this sample. Specifically, the spectrum selected for this purpose was that with $\mathbf{B} / / \mathbf{z}$ ' and $\mathbf{B}_{\mu} / / \mathbf{x}$ ' (Fig. 1a), in which all spectral lines of ' $a$ ' and ' $b$ ' are best separated and are not appreciably affected by magnetic-site splittings (Chen et al. 2002a, b). The actual orientation of the crystal for the spectrum with $\mathbf{B} / / \mathbf{z}$ ' and $\mathbf{B}_{\mu} / / \mathbf{x}$ ' was determined by angle correction on the basis of all spectra in plane $x^{\prime} z$ ' and using the spinhamiltonian parameters of centers 'a' (Chen et al. 2002a), obtained with the EPR-NMR software package of Mombourquette et al. (1996). Spectral simulations for centers ' $a$ ' and ' $b$ ' at $\mathbf{B} / / \mathbf{z}$ ' and $\mathbf{B}_{\mu} / / \mathbf{x}$ ' were first made separately by use of their respective spinhamiltonian parameters, measured linewidths and appropriate lineshapes (i.e., lorentzian; Chen et al. 2002a, b) and were then added together for various trial proportions (Fig. 2). These simulated spectra were then compared with the observed spectrum by minimizing their differences using the criterion $\Sigma\left(\mid \mathrm{I}_{\text {observed }}-\right.$ $\left.I_{\text {simulated }} \mid\right) / \Sigma\left|I_{\text {observed }}\right|$, where the symbol I represents EPR absorption intensities (i.e., areas) and the sum $\Sigma$ is over all electronic transitions.

The simulated spectrum giving the best fit for the observed spectrum of sample AP30-1 has an 'a'/'b' value of 2.0(6) (Fig. 2), corresponding to a site-occupancy ratio of $\mathrm{Gd}$ between the $\mathrm{Ca} 2$ and $\mathrm{Ca} 1$ sites (i.e., ${ }^{\mathrm{Ca} 2} \mathrm{Gd} /{ }^{\mathrm{Ca} 1} \mathrm{Gd}$ ) of $1.4(4)$; the multiplicities of $\mathrm{Ca} 2$ and Ca1 sites are 6 and 4, respectively (Hughes et al. 1989). Note that the uncharacterized centers, related to $\mathrm{Gd}^{3+}$ ions or not, account for only approximately $5 \%$ of the total observed spectrum in AP30-1 and therefore are not expected to cause significant deviations from the site-occupancy ratio that is based on centers ' $a$ ' and ' $b$ '.
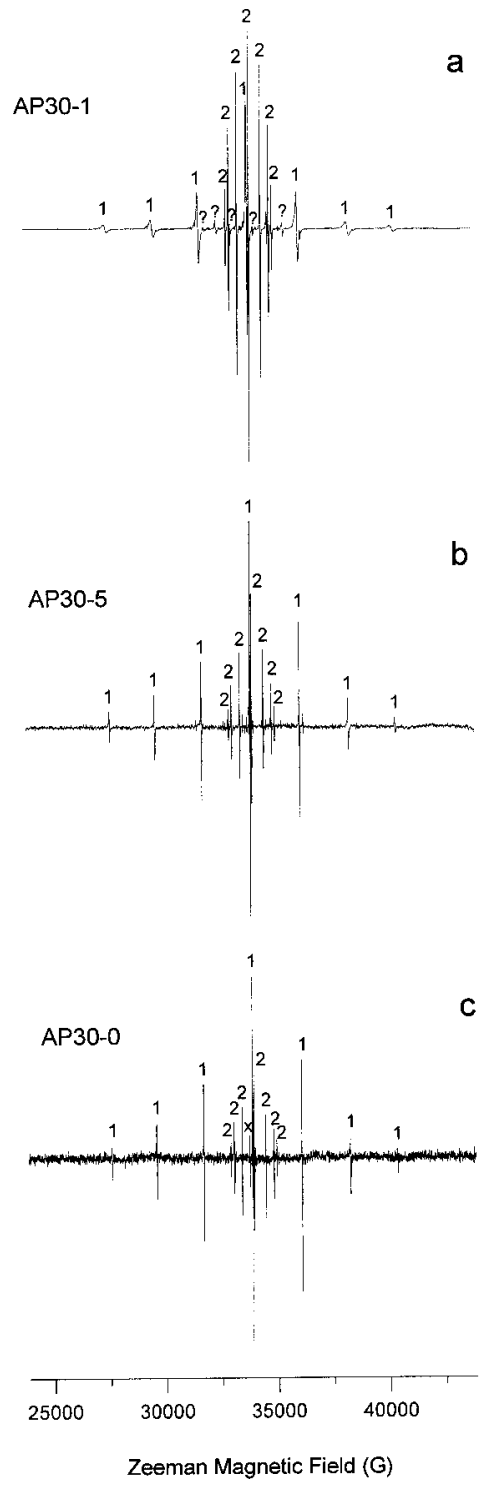

FIG. 1. Single-crystal W-band EPR spectra, with $\mathbf{B} / / \mathbf{z}$ ' and $\mathbf{B}_{\mu} / / \mathbf{x}$ ': a) AP30-1 containing 1.2(2) wt $\% \mathrm{Gd}_{2} \mathrm{O}_{3}$, measured at $\mathrm{T} \approx 287 \mathrm{~K}$, frequency $=94.3767 \mathrm{GHz}$ and spectral resolution of $\sim 4.9$ G. b) AP30-5 containing 57(4) ppm Gd (Chen et al. 2002b), and c) AP30-0 containing 0.8 (1) ppm Gd (Pan et al. 2002), collected at similar orientations and experimental conditions, are shown for comparison. Note that centers ' $b$ ' and ' $a$ ' corresponding to $\mathrm{Gd}^{3+}$ at the $\mathrm{Ca} 1$ and $\mathrm{Ca} 2$ sites are labeled as " 1 " and " 2 "; other spectral lines of unknown center(s) in AP30-1 are marked by "?". Center Mn corresponding to ${ }^{55} \mathrm{Mn}^{2+}$ at the Ca1 site is evident in AP30-5, and an as-yet uncharacterized defect center possibly involving two ${ }^{19} \mathrm{~F}$ or ${ }^{31} \mathrm{P}$ nuclei (Pan et al. 2002) in AP30-0 is labeled as " $x$ ". Note that the relative intensities of ' $a$ ' and ' $b$ ' in AP30-1 are opposite to those in AP30-0 and AP30-5. 


\section{Single-crystal X-ray structure refinements}

The precise X-ray reflection intensities measured in this study confirm the observations of our previous Xray study; the FAp crystals of AP30-1 are not twinned (Chen et al. 2002a). The X-ray structure refinements of AP30-1 and AP40-0 closely followed the procedures of Fleet \& Pan (1995) and Fleet et al. (2000a, b), who investigated hydrothermally grown apatite, refined the $R E E$ occupancy of the $\mathrm{Ca} 2$ site, and assumed that the total occupancy of both $\mathrm{Ca} 1$ and $\mathrm{Ca} 2$ positions is unity (i.e., that all formulae are stoichiometric). For the present crystals of Gd-bearing FAp, the Gd occupancy of the $\mathrm{Ca} 2$ position was refined, and the total cation occupancy of $\mathrm{Ca} 1$ and $\mathrm{Ca} 2$ was constrained to be equal but less than unity, as required by the EPMA data (this is a refinement of type-1 in Table 4). The resulting siteoccupancy ratios $\left({ }^{\mathrm{C} 2} \mathrm{Gd} /{ }^{\mathrm{Ca}} \mathrm{Gd}\right)$ are $3.1(6)$ for AP40-0 and 0.8(2) for AP30-1. The Gd occupancy of the Ca1 position was refined (i.e., refinement of type 2 in Table 4); the ${ }^{\mathrm{Ca} 2} \mathrm{Gd} /{ }^{\mathrm{Ca} 1} \mathrm{Gd}$ value is $2.8(3)$ for AP40-0 and 1.2(2) for AP30-1, values that are broadly within a one-sigma standard deviation of the type-1 refinement. The assumed nonstoichiometry for AP40-0 [the total

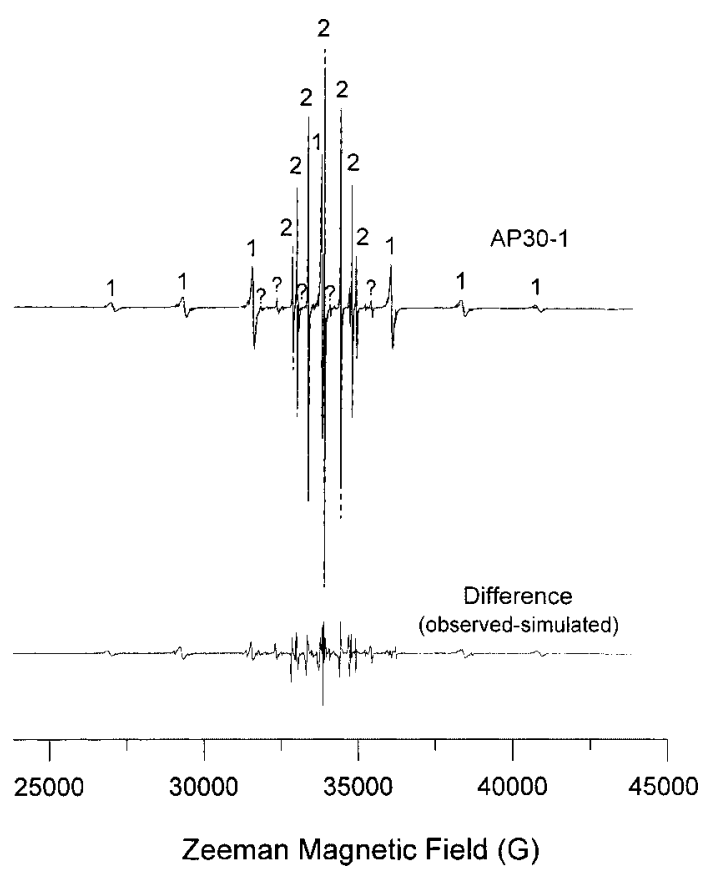

FIG. 2. Comparison of observed (solid line) and simulated [dashed line; ${ }^{\mathrm{Ca} 2} \mathrm{Gd} /{ }^{\mathrm{Ca} 1} \mathrm{Gd}=1.4(4)$ ] single-crystal W-band EPR spectra of AP30-1, with $\mathbf{B} / / \mathbf{z}$ and $\mathbf{B}_{\mu} / / \mathbf{x}^{\prime}$, at 287 $\mathrm{K}$, frequency $=94.3767 \mathrm{GHz}$ and spectral resolution of $\sim 4.9$ G. Also shown is the difference between the observed and simulated spectra. content of cation vacancies is 0.03 per formula unit (pfu), Table 2] is relatively insignificant compared to the Gd content ( 0.17 atoms $p f u$ ), but that for AP30-1 (total cation vacancy content: $0.03 \mathrm{pfu}$ ) is possibly significant (the Gd content is 0.06 atoms $p f u$ ), and may have introduced a significant error in the refined siteoccupancy ratio. However, refinement of AP30-1 assuming a total occupancy of unity for Ca1 (refinement of type 3 in Table 4) gave a site-occupancy ratio consistent with the previous two refinements. Therefore, uncertainty in apatite composition (including vacancies), as estimated from EMPA, is unlikely to significantly affect the calculated site-occupancy ratios of Gd. Finally, when the occupancies of $\mathrm{Ca}$ in $\mathrm{Ca} 1$ and $\mathrm{Ca} 2$ are varied along with $\mathrm{Gd}$ in $\mathrm{Ca} 2$ (refinement of type 4 in Table 4), a higher value of 1.7(7) is obtained for the site-occupancy ratio. This refinement did converge (albeit slowly), but the resulting site-occupancy ratio is suspect, because the $\mathrm{Gd}$ and $\mathrm{Ca}$ occupancies are now highly correlated.

\section{Discussion}

\section{Comparison of site-occupancy ratios \\ from $W$-band EPR and X-ray structure methods}

The X-ray structure refinement of AP40- 0 containing 2.9(1) $\mathrm{wt} \% \mathrm{Gd}_{2} \mathrm{O}_{3}$ shows that $\mathrm{Gd}$ in this sample has a marked preference for the $\mathrm{Ca} 2$ position. This site preference is similar to that observed by Mackie \& Young (1973), who reported that $\mathrm{Nd}$ in $\mathrm{Nd}_{2} \mathrm{O}_{3}$-doped FAp occupies exclusively the $\mathrm{Ca} 2$ position. Similarly, Fleet \& Pan (1995) reported that the site-occupancy ratios of $R E E$ in FAp decrease monotonically with increase in atomic number through the $4 f$ transition series (see also Hughes et al. 1991, Fleet et al. 2000a, b) and reported a ${ }^{\mathrm{Ca}} 2 \mathrm{Gd} /{ }^{\mathrm{Cal}} \mathrm{Gd}$ value of 2.03 for a hydrothermally grown

TABLE 4. SITE OCCUPANCIES OF Gd IN SYNTHETIC FLUORAPATITE

\begin{tabular}{|c|c|c|c|c|}
\hline & & \multicolumn{2}{|c|}{ Site occupancies of Gd } & \multirow{2}{*}{$\begin{array}{l}\text { site- } \\
\text { occu- } \\
\text { pancy } \\
\text { ratio* }\end{array}$} \\
\hline \multicolumn{2}{|c|}{ Refinement } & Cal & $\mathrm{Ca} 2$ & \\
\hline \multicolumn{5}{|c|}{ AP30-1 } \\
\hline 1 & $\mathrm{Gd}$ in $\mathrm{Ca} 2$ & 0.00245 & $0.00288(38)$ & $0.8(2)$ \\
\hline 2 & $\mathrm{Gd}$ in $\mathrm{Ca} l$ & $0.00189(22)$ & 0.00344 & $1.2(2)$ \\
\hline 3 & Gd in $\mathrm{Ca} 2$; $\mathrm{Cal}$ full & 0.00212 & $0.00321(38)$ & $1.0(3)$ \\
\hline 4 & $\mathrm{Gd}$ in $\mathrm{Ca} 2, \mathrm{Ca}$ in $\mathrm{Ca} 1, \mathrm{Ca} 2$ & 0.00149 & $0.00384(37)$ & $1.7(7)$ \\
\hline \multicolumn{5}{|c|}{ AP40-0 } \\
\hline 1 & $\mathrm{Gd}$ in $\mathrm{Ca} 2$ & 0.00250 & $0.01142(40)$ & $3.1(6)$ \\
\hline 2 & $\mathrm{Gd}$ in $\mathrm{Cal}_{\mathrm{l}}$ & $0.00272(23)$ & 0.01121 & $2.8(3)$ \\
\hline
\end{tabular}

Type of refinement: 1 . Gd in Ca2 varied, $\square_{\mathrm{Cal}}=\square_{\mathrm{Ca}} ; 2$. Gd in Ca1 varied, $\square_{\mathrm{Cal}}=$ $\square_{\mathrm{Ca} 2} ; 3$. $\mathrm{Gd}$ in $\mathrm{Ca} 2$ varied, $\square_{\mathrm{Ca} 1}=0 ; 4$. $\mathrm{Gd}$ in $\mathrm{Ca} 2$, $\mathrm{Ca}$ in $\mathrm{Ca}$ and $\mathrm{Ca}$ in $\mathrm{Ca} 2$ varied, $\square_{\mathrm{CA1}}=\square_{\mathrm{Ca2}}$. Site-occupancy ratio: ${ }^{\mathrm{C2} 2} \mathrm{Gd} /{ }^{\mathrm{Ca} 1} \mathrm{Gd}$. 
Gd-rich FAp. Conversely, the structure refinement of AP30-1, containing only $1.2(2) \mathrm{wt} \% \mathrm{Gd}_{2} \mathrm{O}_{3}$, indicates a site-occupancy ratio close to unity. Although the content of Gd in this apatite is approaching the limit of detection by the structure-refinement method, the differences in Gd site occupancies between the type-1 and type-2 refinements (Table 4) are equivalent to about 0.4 electrons, which are still well within the intrinsic sensitivity of the method. The discrepancy in the siteoccupancy ratio for these two refinements of AP30-1 is the result of systematic errors in the reflection data, which, of course, become significant as the theoretical limit of the method is approached. The site-occupancy ratio from the type- 1 refinement, in which the Gd content of the $\mathrm{Ca} 2$ position was refined, $[0.8(2)]$ is the preferred value because this refinement procedure was adopted in all of our previous structural studies on REEsubstituted apatite-group minerals (Fleet \& Pan 1995, 1997a, Fleet et al. 2000a, b).

The progressive change in size of the $(\mathrm{Ca} 1) \mathrm{O}_{9}$ polyhedron with increasing Gd content from FAp (Sudarsanan et al. 1972) to AP30-1, AP40-0, and the Gd-rich FAp of Fleet \& Pan (1995) supports the presently accepted site-occupancy ratio for Gd in AP30-1. The spatial accommodation of $R E E^{3+}$ cations and anions $X\left(\mathrm{~F}^{-}\right.$, $\mathrm{OH}^{-}$and $\mathrm{Cl}^{-}$) in the apatite structure was discussed in Fleet et al. (2000a, b). The two Ca positions (Ca1, Ca2) offer quite different stereochemical environments. The nearest-neighbor environment of the $\mathrm{Ca} 1$ position (site symmetry 3 ) is a $\mathrm{CaO}_{9}$ tricapped trigonal prism, which also can be regarded as a $6+3$ coordination-polyhedron sphere, whereas that of $\mathrm{Ca} 2$ (site symmetry $m$ ) is a $\mathrm{CaO}_{6} \mathrm{X}$ irregular polyhedron. The bond distances and volumes of both $(\mathrm{Ca} 1) \mathrm{O}_{9}$ and $(\mathrm{Ca} 2) \mathrm{O}_{6} X$ polyhedra increase progressively with increase in radius and content of substituting $R E E^{3+}$ cation, and with increase in size and content of the anion $X$ (from $\mathrm{F}^{-}$to $\mathrm{OH}^{-}$and $\mathrm{Cl}^{-}$).
However, the dimensions of the $(\mathrm{Ca} 1) \mathrm{O}_{9}$ polyhedron are more sensitive to incorporation of $R E E$, and those of the $(\mathrm{Ca} 2) \mathrm{O}_{6} X$ polyhedron, to occupancy of the anion site $X$. As shown in Figure $3 \mathrm{a}$ and Table 3, and using the FAp of Sudarsanan et al. (1972) and the Gd-rich FAp of Fleet \& Pan (1995) as reference compounds, the $\mathrm{Ca} 1-\mathrm{O}$ bond distances and $(\mathrm{Ca} 1) \mathrm{O}_{9}$ polyhedron volume of AP30-1 and AP40-0 are consistent with the Gd siteoccupancy data in $\mathrm{Ca} 1$, as obtained from the type-1 refinement. However, the bond distances and volumes for the $(\mathrm{Ca} 2) \mathrm{O}_{6} X$ polyhedron are not informative in this respect (Fig. 3b, Table 3). The response of this cation polyhedron to replacement of $\mathrm{Ca}$ by small amounts of the heavy $R E E$ is markedly non-linear. As noted in Fleet et al. (2000b), the Ca2-O3 distance of 2.384 is distinctly anomalous, and represents an abrupt discontinuity in the change of this bond length with progressive substitution toward end-member FAp. The other bond distances and the $(\mathrm{Ca} 2) \mathrm{O}_{6} X$ polyhedral volume vary erratically. The $(\mathrm{Ca} 2) \mathrm{O}_{6} X$ polyhedron forms a trigonal cluster around the $X$ anion in the c-axis channels, and the $\mathrm{Ca} 2$ cation is significantly underbonded on its channel side. In contrast, the nine oxygen atoms of the (Ca1) $\mathrm{O}_{9}$ polyhedron enclose the Ca1 cation more-or-less symmetrically, so that this polyhedron responds proportionately to replacement of $\mathrm{Ca}$ ions by the $R E E$. The variation in unit-cell volume with total Gd content is also nonlinear (Fig. 3c) and again signals some complexity in the response of the FAp structure to replacement of $\mathrm{Ca}$ by the heavy $R E E$.

In particular, the ${ }^{\mathrm{Ca} 2} \mathrm{Gd} /{ }^{\mathrm{Ca} 1} \mathrm{Gd}$ value of $\mathrm{AP} 30-1$ obtained from the single-crystal W-band EPR technique (Fig. 2) is within one standard deviation of that from Xray structure refinement (Table 4 ). This agreement between the single-crystal W-band EPR and X-ray structural data confirms that EPR is capable of determining the distribution of paramagnetic trace elements
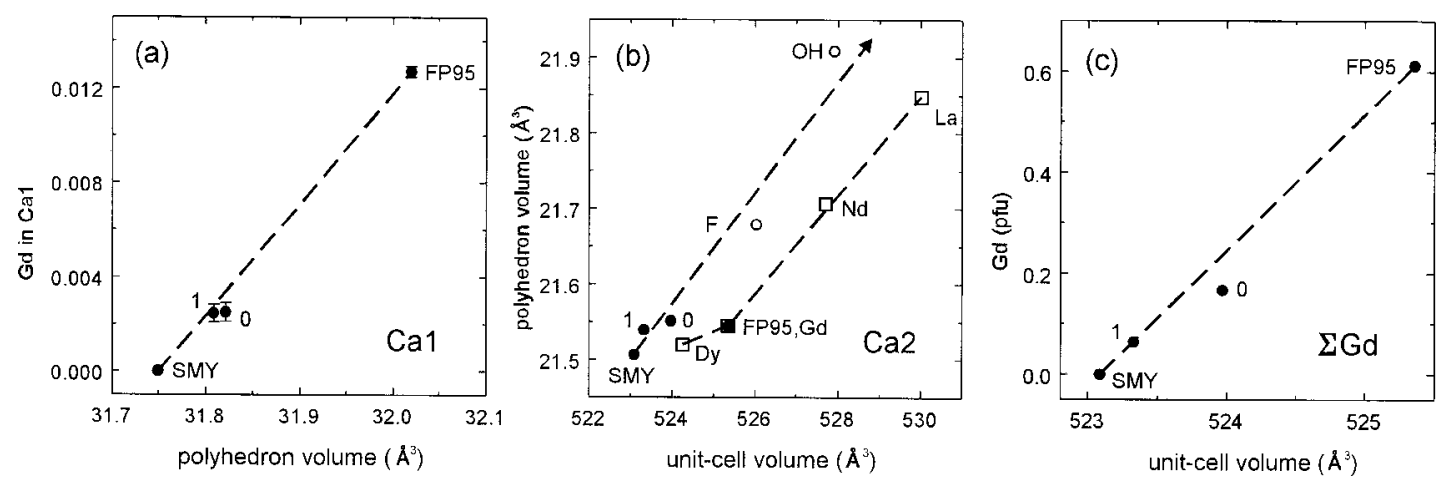

FIG. 3. Variation in: a) Gd occupancy in $\mathrm{Ca} 1$ position with $(\mathrm{Ca} 1) \mathrm{O}_{9}$ polyhedral volume, and b) (Ca2) $\mathrm{O}_{6} X$ polyhedral volume and c) total Gd content with unit-cell volume. Here, 1 is AP30-1; 0 is AP40-0; SMY is FAp of Sudarsanan et al. (1972); FP95 is Gd-FAp of Fleet \& Pan (1995); Dy, Gd, Nd, and La are Dy-FAp, Gd-FAp, Nd-FAp, and La-FAp of Fleet \& Pan (1995); and $\mathrm{F}$ and $\mathrm{OH}$ are (F,OH)Ap and OHAp of Hughes et al. (1989). 
between structurally nonequivalent positions in minerals and their synthetic analogues. Care must be exercised in site-occupancy determination by EPR spectroscopy, however, because some paramagnetic trace elements may not be detectable under certain experimental conditions (e.g., microwave frequencies, sample temperatures). For example, the X-band EPR spectra of AP30-1 disclosed only the presence of center 'a' (Chen et al. 2002a), whereas the higher-frequency W-band spectra (e.g., Fig. 1a) clearly demonstrate that $\mathrm{Gd}$ is not exclusively restricted to the $\mathrm{Ca} 2$ site in this sample. These results point to the advantage of multi-frequency EPR studies. For example, lower frequencies $(v)$ permit the investigation of relatively larger samples, which generally is convenient (e.g., in orienting single crystals and in yielding simpler spectra in some cases). On the other hand, increases in $v$ not only yield greater sensitivity per sample volume but also can lead to easier spectral analyses, enabling discrimination between B-dependent terms and B-independent terms in the spin-hamiltonian of a given species, as well as better discrimination between spectra of different species. Of particular w2relevance to the monitoring of the Gd centers ' $a$ ' and ' $b$ ' of this study is the fact that higher frequencies $h v$ enable observation of some of the magnetic species that are EPR-silent at lower frequencies (thus, ' $b$ ' is not spectroscopically active at the X-band frequency, but is "loud and clear" at the W-band frequency) because the spin-energy-level separation can then be spanned by the photon energy $(\hbar v)$.

\section{Controls of substitution mechanisms on site occupancies}

The ${ }^{\mathrm{Ca} 2} \mathrm{Gd} /{ }^{\mathrm{Ca} 1} \mathrm{Gd}$ value $1.4(4)$ of sample AP30-1 is significantly higher than those of AP30-0 (0.13; Pan et al. 2002) and AP30-5 (0.20; Chen et al. 2002b). Chen et al. (2002b) first noted that the marked preference of Gd for the Ca1 site in flux-grown AP30-5 is opposite to that in the hydrothermally grown Gd-rich FAp of Fleet \& Pan (1995). Chen et al. attributed this discrepancy to: 1) different temperatures of synthesis, and 2) the presence of charge-compensating $\mathrm{Na}^{+}$and $\mathrm{Si}^{4+}$ ions for the incorporation of $\mathrm{Gd}$ into the latter. However, sample AP30-1 was synthesized under the same temperature conditions and from similar starting materials (i.e., without $\mathrm{Na}$ or $\mathrm{Si}$ ) as AP30-0 and AP30-5. Therefore, the two factors proposed by Chen et al. (2002b) cannot be responsible for the marked increase in ${ }^{\mathrm{Ca} 2} \mathrm{Gd} /{ }^{\mathrm{Ca} 1} \mathrm{Gd}$ in going from AP30-0 and AP30-5 to AP30-1, although they most likely have contributed, at least partly, to the absolute abundances of Gd in FAp (see below).

On the basis of the local structural environments of centers ' $a$ ' and 'b', Chen et al. (2002a, b) showed that $\mathrm{Gd}^{3+}$ ions are incorporated into the seven-coordinated $\mathrm{Ca} 2\left({ }^{\mathrm{VII}} \mathrm{Ca}\right)$ and nine-coordinated $\mathrm{Ca} 1\left({ }^{\mathrm{IX}} \mathrm{Ca}\right)$ sites of the flux-grown FAp via the following two types of substitutions:

$$
{ }^{\mathrm{VII}} \mathrm{Gd}^{3+}+\mathrm{O}^{2-}={ }^{\mathrm{VII}} \mathrm{Ca}^{2+}+\mathrm{F}^{-}
$$

and

$$
2^{\mathrm{IX}} \mathrm{Gd}^{3+}+{ }^{\mathrm{VII}} \square=2^{\mathrm{IX}} \mathrm{Ca}^{2+}+{ }^{\mathrm{VII}} \mathrm{Ca}^{2+}
$$

Here, substitution (2) indicates that the incorporation of $\mathrm{Gd}^{3+}$ into the Cal site involves a $\mathrm{Ca}^{2+}$ vacancy $(\square)$ located at the next-nearest-neighbor $\mathrm{Ca} 2$ site (Chen et al. $2002 b$ ). Therefore, this substitution is controlled by the availability of such vacancies at the $\mathrm{Ca} 2$ site in FAp. Although the flux method of Prener (1967) is known to produce highly stoichiometric crystals of FAp (Elliott 1994), point defects such as $\mathrm{Ca}^{2+}$ (and $\mathrm{F}^{-}$) vacancies along the $c$-axis channels (Serret et al. 2000, Pan and Fleet 2002) are expected to be readily available at ppmand sub-ppm concentrations. Therefore, the marked preference of Gd for the Ca1 site in AP30-0 and AP305 containing only $0.8(1)$ and $57(4)$ ppm Gd, respectively, is most likely related to the availability of $\mathrm{Ca}^{2+}$ vacancies at these concentrations. Calcium (and F) deficiency (i.e., nonstoichiometry) is well known in FAp synthesized from stoichiometric melts (e.g., Mazelsky et al. 1968) and in nature (particularly biogenic apatite; Elliott 1994 and references therein). The maximum Ca deficiency in synthetic FAp corresponds to a loss of 10 at.\% of total Ca (Mazelsky et al. 1968, Elliott 1994). However, $\mathrm{Ca}^{2+}$ vacancies in FAp crystals synthesized from $\mathrm{CaF}_{2}$-rich melts in tightly covered platinum crucibles (Prener 1967) and in sealed platinum capsules (e.g., AP40-0) appear to reach saturation at thousands and hundreds of ppm levels of concentrations, respectively (authors' unpubl. results). Therefore, the amounts of $\mathrm{Ca}^{2+}$ vacancies in AP30-1 and AP40-0 cannot match their respective $\mathrm{Gd}$ contents, hence the opposite sitepreference of Gd (relative to those in AP30-0 and AP30-5). Also, the higher ${ }^{\mathrm{Ca} 2} \mathrm{Gd} /{ }^{\mathrm{Ca}} \mathrm{Gd}$ value in AP400 than that in AP30-1, as observed by X-ray structure refinements (Table 4), is consistent with a lower concentration of vacancies at the $\mathrm{Ca}^{2+}$ sites in the former sample (prepared in a sealed platinum capsule). Therefore, the present study provides further evidence for important controls of substitution mechanisms (Mackie \& Young 1973, Fleet et al. 2000a, b, Pan \& Fleet 2002), particularly the roles of point defects, at ppm- and subppm-concentrations, on the site occupancies of REE in apatite-group minerals.

The Gd content in FAp AP40-0 is significantly lower than that in the hydrothermally grown Gd-rich FAp of Fleet \& Pan (1995), despite similar $\mathrm{Gd}_{2} \mathrm{O}_{3}$ contents in their starting materials. This discrepancy is partly attributable to the absence of extraneous chargecompensating ions (e.g., $\mathrm{Na}^{+}$and $\mathrm{Si}^{4+}$ ) for the incorporation of $\mathrm{Gd}$ into the $\mathrm{Ca}$ positions in AP40-0. By analogy with other flux-grown FAp (i.e., AP30-0, AP30-1 and AP30-5), the $\mathrm{Gd}^{3+}$ ions in AP40-0 are most likely incorporated into the Ca sites via substitu- 
tions (1) and (2). These two substitutions can be re-written as exchange reactions

$$
\begin{aligned}
& {[\mathrm{CaO}]+\left[\mathrm{CaF}_{2}\right]+2 \mathrm{Gd}^{3+}+2 \mathrm{O}^{2-}} \\
& =2\left[\mathrm{GdO}_{1.5}\right]+2 \mathrm{Ca}^{2+}+2 \mathrm{~F}^{-}
\end{aligned}
$$

and

$$
3[\mathrm{CaO}]+2 \mathrm{Gd}^{3+}+\square=2\left[\mathrm{GdO}_{1.5}\right]+3 \mathrm{Ca}^{2+}
$$

between FAp crystals and $\mathrm{CaF}_{2}$-rich melts, where $[\mathrm{CaO}],\left[\mathrm{CaF}_{2}\right]$ and $\left[\mathrm{GdO}_{1.5}\right]$ represent these components in the melts. The use of $\mathrm{CaF}_{2}$ as the flux material in the synthesis of AP40-0 is expected to limit the incorporation of $\mathrm{Gd}$ into the $\mathrm{Ca} 2$ site by reaction (3). Similarly, as discussed above, the availability of $\mathrm{Ca}^{2+}$ vacancies at the Ca2 site in FAp crystals is likely to be the most important limiting factor in the incorporation of Gd into the $\mathrm{Ca} 1$ site. Therefore, the use of $\mathrm{CaF}_{2}$-rich melts and the limited availability of $\mathrm{Ca}^{2+}$ vacancies, together with the absence of charge-compensating ions, are most likely responsible for the low Gd content in FAp of AP40-0.

Finally, the marked preference of $\mathrm{Gd}$ for the Ca1 site in AP30-0 and AP30-5 is expected to exert significant controls on the uptake of REE in FAp at ppm- and sub$\mathrm{ppm}$-concentrations, because of the distinct stereochemical environments of the two Ca sites in this mineral (Fleet \& Pan 1997b). Experimental studies are currently under way to determine the partition coefficients of $R E E$ between FAp and $\mathrm{CaF}_{2}$-rich melts over a wide range of $R E E$ concentrations, with emphasis on the effects of defect equilibria on the uptake of the REE in FAp at ppm- and sub-ppm-concentrations that are commonly observed in natural apatite-group minerals.

\section{ACKNOWLEDGEMENTS}

We thank J.M. Hughes, R.F. Martin, M. Plötze and M. Raudsepp for constructive reviews and helpful suggestions, T. Bonli and M. Liu for assistance with the electron-microprobe analyses, and the Natural Sciences and Engineering Research Council (NSERC) of Canada as well as the National Institute of Health (NIH, U.S.A.) for financial support.

\section{REFERENCES}

Calas, G. (1988): Electron paramagnetic resonance. In Spectroscopic Methods in Mineralogy and Geology (F.C. Hawthorne, ed.). Rev. Mineral. 18, 513-571.

Chen, Ning, Pan, Yuanming \& Weil, J.A. (2002a): Electron paramagnetic resonance spectroscopic study of synthetic fluorapatite. I. Local structural environment and substitution mechanism of $\mathrm{Gd}^{3+}$ at the $\mathrm{Ca} 2$ site. Am. Mineral. 87, $37-46$.
\& NiLges, M.J. (2002b):

Electron paramagnetic resonance spectroscopic study of synthetic fluorapatite. II. $\mathrm{Gd}^{3+}$ at the $\mathrm{Ca} 1$ site, with a neighboring Ca2 vacancy. Am. Mineral. 87, 47-55.

Dymek, R.F. \& OwEns, B.E. (2001): Petrogenesis of apatiterich rocks (nelsonites and oxide-apatite gabbronorites) associated with massif anorthosites. Econ. Geol. 96, 797815.

Elliott, J.C. (1994): Structure and Chemistry of the Apatites and Other Calcium Orthophosphates. Elsevier, Amsterdam, The Netherlands.

FleEt, M.E. \& PAN, YuANMING (1995): Site preference of rare earth elements in fluorapatite. Am. Mineral. 80, 329-335.

\& (1997a): Site preference of rare earth elements in fluorapatite: binary (LREE+HREE)-substituted crystals. Am. Mineral. 82, 870-877.

\& (1997b): Rare earth elements in apatites: uptake from $\mathrm{H}_{2} \mathrm{O}$-bearing phosphate-fluoride melts and the role of volatile components. Geochim. Cosmochim. Acta 61, 4745-4760.

, LiU, Xiao Yang \& Pan, Yuanming (2000a): Rareearth elements in chlorapatite $\left[\mathrm{Ca}_{10}\left(\mathrm{PO}_{4}\right)_{6} \mathrm{Cl}_{2}\right]$ : uptake, site preference, and degradation of monoclinic structure. Am. Mineral. 86, 1437-1446.

\& (2000b): Site preference of rare earth elements in hydroxyapatite $\left[\mathrm{Ca}_{10}\left(\mathrm{PO}_{4}\right)_{6}(\mathrm{OH})_{2}\right]$. J. Solid State Chem. 149, 391-398.

Gromet, L.P. \& SiLVER, L.T. (1983): Rare earth element distributions among minerals in a granodiorite and their petrologic implications. Geochim. Cosmochim. Acta 47, 925-939.

Hughes, J.M., Cameron, M. \& Crowley, K.D. (1989): Structural variations in natural $\mathrm{F}, \mathrm{OH}$, and $\mathrm{Cl}$ apatites. $\mathrm{Am}$. Mineral. 74, 870-876.

\& MARIANO, A.N. (1991): Rare-earthelement ordering and structural variations in natural rareearth-bearing apatites. Am. Mineral. 76, 1165-1173.

IBERs, J.A. \& Hamilton, W.C., eds. (1974): International Tables for X-ray Crystallography 4. Kynoch Press, Birmingham, U.K.

Kovalenko, V.I., Antipin, V.S., Vladykin, N.V., SMIRnOVA, Y.V. \& Balashov, Y.A. (1982): Rare-earth distribution coefficients in apatite and behavior in magmatic processes. Geochem. Int. 19(1), 171-183.

Mackie, P.E. \& Young, R.A. (1973): Location of Nd dopant in fluorapatite, $\mathrm{Ca}_{5}\left(\mathrm{PO}_{4}\right)_{3} \mathrm{~F}: \mathrm{Nd}$. J. Appl. Crystallogr. 6, 2631.

Mazelsky, R., Hopkins, R.H. \& Kramer, W.E. (1968): Czochralski growth of calcium fluorophosphates. J. Crystal Growth 3-4, 360-364. 
Mombourquette, M.J., Weil, J.A. \& McGavin, D.G. (1996): EPR-NMR User's Manual. Department of Chemistry, University of Saskatchewan, Saskatoon, Saskatchewan S7N 6C9, Canada. This program is available from the fourth author.

Pan, Yuanming, Chen, Ning, Weil, J.A. \& Nilges, M.J. (2002): Electron paramagnetic resonance spectroscopic study of synthetic fluorapatite. III. Structural characterization of sub-ppm-level $\mathrm{Gd}$ and $\mathrm{Mn}$ in minerals at W-band frequency. Am. Mineral. 87 (in press).

\& FLEET, M.E. (1996): Rare earth element mobility during prograde granulite-facies metamorphism: significance of fluorine. Contrib. Mineral. Petrol. 123, 251-262.

$$
\&
$$

(2002): Composition of the apatitegroup minerals: substitution mechanisms and controlling factors. Rev. Mineral. Geochem. (in press)

\& Stauffer, M.L. (2000): Cerium anomaly and $\mathrm{Th} / \mathrm{U}$ fractionation in the $1.85 \mathrm{Ga}$ Flin Flon paleosol: clues from REE- and U-rich accessory minerals and implications for paleoatmospheric reconstruction. Am. Mineral. 85, 898911

Prener, J.S. (1967): The growth and crystallographic properties of calcium fluor- and chlorapatite crystals. $J$. Electrochem. Soc. 114, 77-83.

Schindler, P. \& GHose, S. (1970): Electron paramagnetic resonance of $\mathrm{Mn}^{2+}$ in dolomite and magnesite and $\mathrm{Mn}^{2+}$ distribution in dolomites. Am. Mineral. 55, 1889-1896.

Serret, A., Cabnas, M.V. \& Vallet-Regi, M. (2000): Stabilization of calcium oxyapatites with lanthanum(III)created anionic vacancies. Chem. Materials 12, 3836-3841.
Stormer, J.C., Jr., Pierson, M.L. \& TACker, R.C. (1993): Variation of $\mathrm{F}$ and $\mathrm{Cl} \mathrm{X}$-ray intensity due to anisotropic diffusion in apatite during electron microprobe analysis. Am. Mineral. 78, 641-648.

Sudarsanan, K., Mackie, P.E. \& Young, R.A. (1972): Comparison of synthetic and mineral fluorapatite, $\mathrm{Ca}_{5}\left(\mathrm{PO}_{4}\right)_{3} \mathrm{~F}$, in crystallographic detail. Materials Res. Bull. 7, 1331-1338.

WARREN, R.W. (1970): EPR of $\mathrm{Mn}^{+2}$ in calcium fluorophosphate. I. The Ca(II) site. Phys. Rev. B2, 4383-4388.

Watson, E.B. \& CAPOBIANCO, C.J. (1982): Phosphorus and rare-earth elements in felsic magmas: an assessment of the role of apatite. Geochim. Cosmochim. Acta 45, 2349-2358.

\& HARRISON, T.M. (1984): Accessory minerals and the geochemical evolution of crustal magmatic systems: a summary and prospectus of experimental approaches. Phys. Earth Planet. Interior 35, 19-30.

Weil, J.A., Bolton, J.R. \& Wertz, J.E. (1994): Electron Paramagnetic Resonance: Elementary Theory and Practical Applications. John Wiley \& Sons Inc., New York, N.Y.

Young, E.J., Myers, A.T., Munson, E.L. \& Conklin, N.M. (1969): Mineralogy and geochemistry of fluorapatite from Cerro de Mercado, Durango, Mexico. U.S. Geol. Surv., Prof. Pap. 650-D, 84-93.

Received February 1, 2002, revised manuscript accepted June 8, 2002. 